\title{
Effect of acceptance and commitment therapy on mood, sleep quality and quality of life in menopausal women: a randomized controlled trial
}

\author{
Zahra Monfaredi ${ }^{1}$, Jamileh Malakouti ${ }^{2}$, Mahmoud Farvareshi ${ }^{3}$ and Mojgan Mirghafourvand ${ }^{4,5^{*}}$
}

\begin{abstract}
Background: One of the most critical periods in a woman's life is menopause. During menopause, depression and anxiety are among the most common mood changes. Sleep disorders also increase during menopause, which leads to quality of life disorders. Different methods such as medication, psychotherapy, or a combination of them are used to treat these disorders. Acceptance and commitment-based therapy is one of the newest methods in psychotherapy that recently has been used a lot. Therefore, this study was conducted to determine the effect of acceptance and commitment therapy (ACT) on mood (primary outcome), sleep quality, and quality of life (secondary outcomes) of menopausal women.
\end{abstract}

Methods: This randomized controlled trial was performed on 86 menopausal women in Tabriz, Iran in 2021. Using the blocking method, participants were randomly assigned into the intervention and control groups. The intervention group received counseling based on ACT approach in 8 sessions of 60 to $90 \mathrm{~min}$. The control group received only routine health care. Depression, Anxiety, Stress Scale-21 (DASS 21), Menopause Quality of Life (MENQOL), and Pittsburgh Sleep Quality Index (PSQI) questionnaires were completed before intervention and immediately after the intervention. Independent t-test and Mann-Whitney $\mathrm{U}$ test were used to compare the outcomes between the two groups.

Results: In terms of sociodemographic characteristics and baseline values of the studied variables, there was no statistically significant difference between the study groups before the intervention. At the end of the intervention, the mean (SD: standard deviation) scores of anxiety, stress, and depression in the counseling group were 2.66 (1.28), 2.91 (1.62), and 1.98 (1.59) and in the control group were 4.19 (1.85), 5.61 (1.49) and 3.59 (1.91). In the intervention group, the mean score of all three variables was significantly lower than the control group $(P<0.001)$. After the intervention, the mean (SD) of the total sleep quality score was 4.04 (2.52) in the counseling group and 4.13 (2.63) in the control group. In addition, the mean (SD) of the total quality of life score was 23.47 (20.13) in the counseling group and 23.14 (17.76) in the control group. Between the study groups, there were no statistically significant differences in the mean of the overall score of sleep quality $(P=0.867)$ and the overall score of quality of life $(P=0.759)$.

\footnotetext{
*Correspondence: mirghafourvand@gmail.com

${ }^{4}$ Social Determinants of Health Research Center, Faculty of Nursing and Midwifery, Tabriz University of Medical Sciences, Shariati Street, P.O. Box: 51745-347, Tabriz 513897977, Iran

Full list of author information is available at the end of the article
}

(C) The Author(s) 2022. Open Access This article is licensed under a Creative Commons Attribution 4.0 International License, which permits use, sharing, adaptation, distribution and reproduction in any medium or format, as long as you give appropriate credit to the original author(s) and the source, provide a link to the Creative Commons licence, and indicate if changes were made. The images or other third party material in this article are included in the article's Creative Commons licence, unless indicated otherwise in a credit line to the material. If material is not included in the article's Creative Commons licence and your intended use is not permitted by statutory regulation or exceeds the permitted use, you will need to obtain permission directly from the copyright holder. To view a copy of this licence, visit http://creativecommons.org/licenses/by/4.0/. The Creative Commons Public Domain Dedication waiver (http://creativeco mmons.org/publicdomain/zero/1.0/) applies to the data made available in this article, unless otherwise stated in a credit line to the data. 
Conclusion: Using ACT-based counseling can improve the mood of menopausal women. However, further randomized clinical trials are needed before making a definitive conclusions.

Trial registration: Iranian Registry of Clinical Trials (IRCT): IRCT20120718010324N65. Date of registration: 2/19/2021. Date of first registration: 2/19/2021. URL: https://en.irct.ir/user/trial/53544/view; Date of recruitment start date: 2/22/2021.

Keywords: Anxiety, Stress, Depression, Quality of life, Sleep quality, Acceptance and commitment therapy, Counseling

\section{Background}

Women experience different periods during their lives and developmental stages. One of the most critical periods in a woman's life is menopause [1]. Menopause is a natural process that is shown by the permanent interruption of the menstrual cycle due to the loss of ovarian function [2]. It takes 2 to 8 years for women to go from premenopausal to menopausal. Due to changes in ovarian function, menstrual cycles in women change during this time. In addition, the hormonal-nervous system that controls ovulation in these women begins to secrete hormones irregularly and at long intervals. Although the main sign of menopause is high follicular stimulating hormone (FSH) levels, Gonadotropin levels remain high during this period [3]. Menopause happens approximately at the age of 50 [4]. The average age of menopause varies by race, genetics, nutrition, physical activity, and sexual behavior $[5,6]$. The average age of menopause in urban, rural, and total population of Iran is respectively 49.9, 49.2, and 49.6years [7].

A wide range of physiological, anatomical, and clinical changes appear in women due to the decreased ovarian function with declining levels of hormones, including estrogen and androgens that vary from woman to woman [8]. In different people, these symptoms can appear as minor discomfort to severe and debilitating symptoms [1]. These symptoms include flushing, menstrual irregularities, feeling of urgency in urination, bladder inflammation, predisposition to urinary tract infections, breast tenderness, vaginal dryness and atrophy, sleep disorders, sexual dysfunction, night sweats, osteoporosis, and other disorders such as depression, anxiety, anger, fatigue and irritability $[9,10]$.

Hormonal changes during menopause may affect mood during this period, for example, depressive and anxiety symptoms have been described among postmenopausal women [11]. According to studies, this mood is changed due to changes in estradiol levels and the association of serum estrogen levels with levels of platelet monoamine oxidase, which is a marker of adrenergic and serotonergic function [12]. In other words, due to decreased self-confidence, lack of activity and mobility, loss of friends and relatives, decreased physical and material independence, and chronic diseases, menopausal women are more exposed to anxiety [13]. Anxiety was independently associated with low quality of life and severe menopausal symptoms based on a study about postmenopausal women [14]. In addition to hormonal changes, other factors are effective in causing and exacerbating mood changes. These factors are the adverse effect of vasomotor symptoms on mood (domino theory), bad events in social life such as illness, previous history of depression, retirement, death of a spouse, care of elderly parents, empty nest syndrome, how women feel about menopause, prolonged menopause, chronic pain and disability, changes in sexual function, the level of emotional intelligence, and menopausal symptoms such as flushing, night sweats, and secondary sleep disorders can also affect mood changes $[15,16]$. It is reported that the prevalence of sleep problems is up to $65 \%$ in menopausal women. Sleep disorders during menopause cause quality of life disorders [17]. It also decreases the ability to perform physical, mental, and social daily activities and affects mood changes in women [18].

Over $75 \%$ of women search for strategies and treatments to reduce menopausal symptoms [19]. Different methods are used to treat these disorders such as medication, psychotherapy, or a combination of them. To reduce flushing, sexual disorders and vaginal dryness, night sweats, restlessness, and urinary disorders, nearly, $40 \%$ of women use medical treatments [20]. Hormone therapy (HRT) is the most effective treatment for vasomotor symptoms of menopause among the pharmacologic therapies so that it treats 80 to $90 \%$ of the symptoms [21]. Due to an increased risk of breast cancer, pulmonary embolism, and cardiovascular disease, the Women's Health Initiative has banned the use of the hormone in menopausal women [2]. Therefore, HRT is not recommended as a first-line treatment for menopausal women due to the complications and risks. Other therapies, including complementary therapies, herbal remedies, pharmacologic therapies, and behavioral modification can be as effective as HRT. It can treat the menopausal vasomotor symptoms [22]. Acceptance and commitment therapy (ACT) is one of the newest methods in psychotherapy which has come to the attention. Psychological 
interventions are used to help individuals to manage the social, emotional, and psychological challenges [23].

ACT dates back to a philosophical theory called functional contextualism. It is performed based on a research program on language and cognition called the theory of the framework of mental relations. ACT has six central processes that lead to psychological flexibility. These six processes include acceptance, diffusion, self as context, communication with the present, values, and committed action [24]. The theory of communication systems is the basis of this treatment. According to this theory, there are many ways to solve our problems but they trap us which leads to our resentment. Avoiding stress and anxiety are considered as the main problem of patients in this treatment, which leads to disability and reduced life satisfaction. According to this theory, when negative thoughts and emotions have an excessive and inappropriate effect on behavior, avoidance occurs. Therefore, exposing the patient to situations that are mostly avoided is the main method of treating ACT [25-27].

Research to date has supported the effectiveness of ACT for the improvement of depression [28, 29], anxiety $[28,30]$, stress $[29,30]$, general mental health [30], insomnia and sleep quality [31], and quality of life [27, 31] among different populations such as unemployed individuals, women with multiple sclerosis, mothers of children with hearing loss, patients with hypertension, social workers, women with breast cancer and pregnant women. Only a research have assessed the effect of $\mathrm{ACT}$ on sexual function in menopausal women [32] and no study focused on the effect of ACT on mood, sleep quality and quality of life in menopausal women. Even though, some studies showed the positive effect of other similar methods used in psychology such as cognitive therapy in improving depression, anxiety, insomnia and quality of life among menopausal woman [33, 34].

Women spend more than a third of their lives during menopause due to the increasing trend of elderly in the world and Iran and increasing life expectancy [35]. These biological and endocrine changes affect a woman's sense of physical and mental health [36, 37]. Therefore, it is important to pay attention to the health of this period and improve the quality of life. On the other hand, depression and anxiety are among the common mood changes during menopause [12]. Due to the side effects of long-term use of drug treatments, alternative psychological therapies can be used [38]. In addition to effectiveness, counseling in this field will reduce overall health costs $[39,40]$. Therefore, this study was conducted to determine the effectiveness of treatment based on acceptance and commitment on mood (primary outcome) and quality of life and sleep quality (secondary outcomes) in menopausal women.

\section{Study hypotheses}

1. The mean depression score is significantly lower in the counseling group compared to the control group.

2. The mean anxiety score is significantly lower in the counseling group compared to the control group.

3. The mean stress score is significantly lower in the counseling group compared to the control group.

4. The mean quality of life score is significantly lower in the counseling group compared to the control group.

5. The mean sleep quality is significantly lower in the counseling group compared to the control group.

\section{Methods}

\section{Study design and participants}

This randomized controlled trial with two parallel groups was performed on 86 postmenopausal women in TabrizIran health centers from March to the end of August 2021.

The inclusion criteria included willingness to participate in the study, having normal menopause, being married, having at least a middle school education, women with less than 10 years of menopause, earning an anxiety score of 4-8 (mild and moderate anxiety), depression score between 5 and 11 (mild and moderate depression), stress score between 8 and 13 (mild and moderate stress) according to DASS questionnaire, having a minimum of 45 years and a maximum of 60 . There are also exclusion criteria such as the use of tobacco and alcoholic beverages and herbal medicines, known systemic problems including cardiovascular, gastrointestinal, liver, blood, endocrine, etc., use of any effective drug against flushing (clonidine, methyldopa, gabapentin, selective serotonin reuptake inhibitors, norepinephrine inhibitors, soy isoflavones), participating in relaxation and yoga classes and not using anti-anxiety drugs, not using sedatives including cinnamon and chamomile.

Based on the results of the study of Shariat Moghani et al. [41], the sample size was calculated 39 people by using the G-power software [42] for stress variable with considering the $M_{1}=7.07$ (mean score of stress subscale of DASS), $\mathrm{M}_{2}=4.59$ (assuming $35 \%$ reduction due to intervention), $\mathrm{SD}_{1}=\mathrm{SD}_{2}=4.33$, one-sided $\alpha=0.05$, and Power $=80 \%$. There were 43 people in each group in the final sample size considering the $10 \%$ attrition.

\section{Sampling}

The researcher referred to the health centers of Tabriz for sampling. Then, a list of all women around menopausal ages ( 45 to 60 years) with their phone numbers and addresses were extracted, menopausal women were called, the goals and methods of the study were briefly 
explained, and the women were examined for inclusion and exclusion criteria. Due to the spread of the coronavirus and compliance with health protocols, they were also asked to be online in the WhatsApp program at a certain time if they are eligible and willing to participate in the study. The objectives of the research were fully explained in the online session. Written informed consent was obtained in a face to face session if the individual tended to participate in the study, then the Depression, Anxiety, Stress Scale-21 (DASS 21) was completed through interviews with participants.

Menopausal women completed the questionnaire of socio-demographic and obstetric characteristics, Menopause Quality of Life (MENQOL) Questionnaire and Pittsburgh Sleep Quality Index (PSQI Index) through interviews if they obtained anxiety score 4 to 8 (mild and moderate anxiety), depression score 5 to 11 (mild and moderate depression), and stress score 8 to 13 (mild and moderate stress). Menopausal women with severe and very severe depression, stress, and anxiety were referred to a psychiatrist.

\section{Randomization}

By using a random blocking method with a 1: 1 allocation ratio, participants were allocated to the intervention (counseling) and control groups. By using Randomiser software [43], the allocation sequence was determined by a person who did not involve in the study and was not aware of the study process. The type of intervention was written on paper and placed in opaque and sealed envelopes that numbered sequentially to conceal the allocation sequence. The envelopes were opened in the order in which the participants entered the study and the type of group of individuals was determined.

\section{Intervention}

For the intervention group, the researcher (first author) held counseling sessions. The counseling sessions were held face to face in a place intended for counseling with a quiet and private environment in health centers. There were 8 counseling sessions. During the sessions, women were given the necessary information, and there were interactive sessions between the counselor and the women. Counseling was performed with an approach based on ACT, during 60-90 min sessions and one session per week, in groups of 8-12 people. It was also held in a place with a suitable space to observe the social distance, proper air conditioning and the observance of health protocols. No one was infected with Covid-19 during study.

Here is the treatment plan of the counseling group meetings:
Session 1: Greeting with members, description of rules and duties of group members, statement of goals, the introduction of counseling based on ACT. General assessment: the main complaint of the participants, identifying the experimental avoidances of the participants, identifying thoughts and feelings behind these actions, identifying the strengths of the participants.

Session 2: Brief description of the anatomy and physiology of the reproductive system (uterus, ovaries, etc.), the definition of menopause, explanation of menopausal symptoms and their effects on various aspects of life, available drug treatments, and non-drugs methods and their success rates.

Session 3: Teaching mindfulness techniques.

Session 4: The technique of frustration using the metaphor of wells and shovels, the practice of suppressing the mind to show the uncontrollability of the mind; Homework: self-monitoring.

Session 5: Assessing homework, teaching the concept of acceptance: using the metaphor of the guest and teaching the concept of the self-observer. Techniques for not taking seriously the thoughts and practicing them: watching thoughts, taking on the role of a TV reporter, or singing thoughts.

Session 6: Introducing the concept of values and committed actions and the difference between values and purpose and introducing the list of values, using the metaphor of birthday party. Homework: Completing the worksheet of goals, values, and effective actions and obstacles.

Session 7: Start the session with contact with the present moment exercises, control, and evaluation of worksheets, introduction, and training of cognitive inconsistencies, using the metaphor of bus.

Session 8: Repetition of mindfulness techniques and retrieval of assignments and review of exercises.

No intervention was applied to the control group and they received only routine care included: control of blood pressure and weight gain, control hot flushes and other menopausal symptoms, breast exam, pelvic exam, prescription to undergoing mammography and Papsmear test [44]. Also, after the completion of the project, the content of the counseling sessions was provided to the participants of the control group.

\section{Data collection tools}

To collect data, the socio-demographic and obstetrics characteristics questionnaire, DASS 21, MENQOL and PSQI were used in this study. The researcher completed the questionnaire before and immediately after the intervention through interviews with participants. 


\section{Socio-demographic and obstetrics characteristics questionnaire}

This questionnaire includes questions such as age, duration of menopause, menopausal age, level of education, occupation, level of education and occupation of spouse and adequacy of family monthly income for living expenses, number of family members, the relation of people living with participant (living with the daughterin-law and son-in-law), body mass index (BMI), cigarette smoking in the participant and her spouse and life satisfaction. Content and face validity were used to determine the validity of the socio-demographic and obstetrics characteristics questionnaire. The questionnaire was given to the faculty members. Based on the feedback received, the corrections were made on the tools after collecting their opinions.

\section{MENQOL}

In this study, to measure specific criteria for the quality of life of postmenopausal women, the MENQOL questionnaire was used. The medical department of the University of Toronto, Canada (1996) prepared and used this questionnaire. MENQOL has been previously used in Iran and in the Yazdkhasti et al.s study [45], the test-retest analysis method was used to determine the reliability this questionnaire and correlation coefficient $(r)$ was reported equal to 0.84 . The questionnaire has 29 closed questions with a rating range of zero to six based on the Likert scale. It includes 4 dimensions, vasomotor (3 questions), psychosocial (7 questions), physical (16 questions), and sexual (3 questions). The quality of life score of menopausal women is calculated from the scores obtained from these 4 subdomains. The minimum and maximum scores obtained in the vasomotor dimension are 0 to 18 , psychosocial 0 to 42 , physical 0 to 96 , and sexual 0 to 18 based on how to score on a 6-point Likert scale and the number of questions available. According to mentioned dimensions, the total score of quality of life is from 0 to 174 . High scores indicate more severe menopausal symptoms and lower quality of life in postmenopausal women [45].

\section{PSQI}

This questionnaire includes 18 questions and seven components including subjective sleep quality, sleep latency, sleep duration, sleep efficacy, sleep disturbances, use of sleep medication and daytime dysfunction. The score of each question is between 0 and 3 and the score of each component is a maximum of 3 . The sum of the average scores of these seven components is the total score of the instrument, which ranges from 0 to 21 . The quality of sleep is lower if the score obtained becomes high. A score higher than 5 indicates poor sleep quality [46]. The
Iranian version of this questionnaire is a valid and reliable tool for measuring sleep quality. According to Nazifi et al., the reliability of this instrument with Cronbach's alpha was reported to be 0.55 [47].

\section{DASS}

This scale includes three subscales of stress, depression, and anxiety. This questionnaire consists of 21 questions. For each of the three subscales, 7 questions are considered $[48,49]$. The scoring for each question is based on the Likert scale from never (0) to very high [3]. The score is calculated for each scale separately and the overall score is not calculated. For each subscale, the minimum score is zero and the maximum is 21 and a higher score indicates a worse situation [50]. The DASS 21 scale can diagnose and screen symptoms of anxiety, depression, and stress over the past week. Menopausal women aged 45-60 years entered the study who received an anxiety score of 4-8 (mild and moderate anxiety), a depression score between 5 to 11 (mild and moderate depression), and a stress score between 8 to13 (mild and moderate stress) from DASS questionnaire. This questionnaire was also validated In Iran and its validity was reported for anxiety subscale 0.73 , depression subscale 0.81 , and stress subscale 0.81 [51].

\section{Data analysis}

The data were analyzed using SPSS-Version 24 software after collecting information from all participants. The normality of quantitative data was assessed using the Kolmogorov - Smirnov test. Chi-square, chi-square for trend, independent $t$, and Fisher's exact tests were used to compare socio-demographic and obstetrics characteristics between the two groups. An independent t-test was used to compare the mean score of variables with normal distribution among study groups. Mann-Whitney U test was used for variables with the non-normal distribution. Within group comparisons were conducted using the Wilcoxon test for variables with the non-normal distribution and paired samples t-test for variables with normal distribution.

All tests were performed based on Intention-To-Treat. $P<0.05$ was considered significant.

\section{Results}

Sampling started in March 2020 and continued until August 2021. The researcher evaluated 125 women aged 45 to 60 years and 86 of them qualified the inclusion criteria. 43 women were allocated randomly to the counseling group, and they participated in 8 counseling sessions. There was no drop in the study. 86 women were retested and the data were analyzed after the intervention (Fig. 1). 


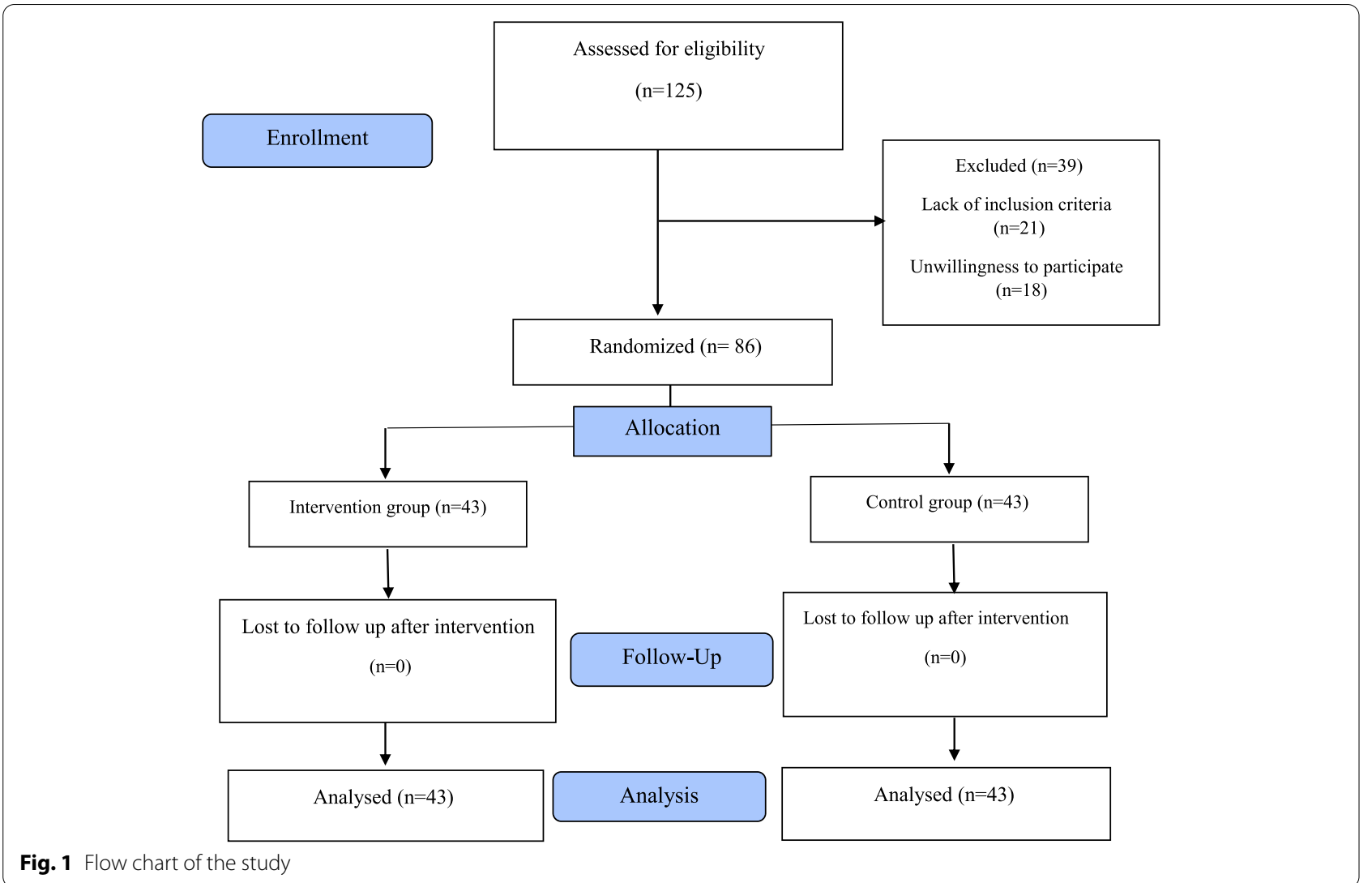

In the intervention group, the mean (SD: standard deviation) age of the counseling group was 54.87 (4.49) and in the control group was 54.75 (4.65) years old. Table 1 shows the socio-demographic and obstetrics characteristics of participants.

Before intervention, based on the Mann-Whitney $\mathrm{U}$ test, there was no statistically significant difference between the two groups in terms of anxiety $(P=0.189)$, stress $(P=0.878)$ and depression $(P=0.611)$. However, after the intervention, the mean score of anxiety, stress and depression was significantly lower in the counseling group than the control group $(P<0.001)$ (Table 2).

According to the Mann-Whitney U test, there was no statistically significant difference between the two groups before $(P=0.548)$ and after the intervention $(P=0.867)$. There was no statistically significant difference between the groups in terms of sleep quality subdomains $(P>0.05)$ (Table 3$)$.

There was no statistically significant difference between the two groups before $(P=0.475)$ and after $(P=0.759)$ the intervention according to the MannWhitney $U$ test. There was no statistically significant difference between the groups in terms of quality of life subdomains $(P>0.05)$ (Table 4$)$.

\section{Discussion}

In our knowledge, this is the first study to examine the effect of ACT-based counseling on mood, sleep quality and quality of life among the menopausal women. According to the study results, in menopausal women, counseling based on ACT approach reduced anxiety, stress, and depression and improved their mood, but it did not affect sleep quality and quality of life.

In the present study, at the end of the intervention, the mean scores of stress, anxiety, and depression in the group receiving counseling based on ACT were significantly lower than the control group. Rajabi et al. (2014) assessed the effectiveness of ACT on anxiety and depression in women with multiple sclerosis. The results showed that ACT reduced anxiety, depression, and experiential avoidance of these women [28]. In addition, ACT reduced the stress and anxiety of Razi Psychiatric Center staff according to a study conducted by Heidari et al. (2018) [52]. Qarashi et al. (2019) conducted a study to investigate the effect of ACT on stress and anxiety of mothers of deaf or hard of hearing children. They showed that this intervention reduces mothers' stress and anxiety [29]. Miri et al. (2021) examined the impact of the ACT counseling on stress and anxiety in patients with 
Table 1 Sociodemographic and obstetrics characteristics in study groups

\begin{tabular}{|c|c|c|c|}
\hline \multirow[t]{2}{*}{ variable } & \multirow{2}{*}{$\begin{array}{l}\text { Counseling group }(n=43) \\
\text { Mean }\left(\mathrm{SD}^{*}\right)\end{array}$} & \multirow{2}{*}{$\begin{array}{l}\text { Control group }(n=43) \\
\text { Mean (SD*) }\end{array}$} & \multirow[t]{2}{*}{$P$-value } \\
\hline & & & \\
\hline Age (Year) & $54.87(4.49)$ & $54.75(4.56)$ & $0.905^{\dagger}$ \\
\hline Menopausal age (Year) & $49.77(3.03)$ & $50.40(3.09)$ & $0.345^{\dagger}$ \\
\hline \multirow[t]{2}{*}{ Body mass index $(\mathrm{kg} / \mathrm{m} 2)$} & $29.45(5.38)$ & $29.13(5.44)$ & $0.786^{\dagger}$ \\
\hline & Number (percent) & Number (percent) & \\
\hline Education & & & $0.375^{\S}$ \\
\hline Secondary school & $28(65.1)$ & $25(58.1)$ & \\
\hline Highschool & $2(4.7)$ & $3(7.0)$ & \\
\hline Diploma & $11(25.6)$ & $9(20.9)$ & \\
\hline University & $2(4.7)$ & $6(14.0)$ & \\
\hline Job & & & $0.534^{\ddagger}$ \\
\hline Housewife & $38(88.4)$ & $36(83.7)$ & \\
\hline Employed & $5(11.6)$ & $7(16.3)$ & \\
\hline Housband education & & & $0.746^{\S}$ \\
\hline lilliterate & $3(7.0)$ & $5(11.6)$ & \\
\hline Elementary school & $5(11.6)$ & $5(11.6)$ & \\
\hline Secondary school & $12(27.9)$ & $11(25.6)$ & \\
\hline Highschool & $5(11.6)$ & $1(2.3)$ & \\
\hline Diploma & $11(25.6)$ & $7(16.3)$ & \\
\hline University & $7(16.3)$ & $14(32.6)$ & \\
\hline Housband job & & & $0.199^{\ddagger}$ \\
\hline Free job & $16(37.2)$ & $7(16.3)$ & \\
\hline Employed & $9(20.9)$ & $12(27.9)$ & \\
\hline Retired & $14(32.6)$ & $19(44.2)$ & \\
\hline Unemployed & $4(9.3)$ & $4(9.3)$ & \\
\hline Laborer & $0(0.0)$ & $1(2.3)$ & \\
\hline Parity & & & $0.273^{\ddagger}$ \\
\hline One & $13(30.2)$ & $20(46.5)$ & \\
\hline Two & $20(46.5)$ & $14(32.6)$ & \\
\hline Three & $10(23.3)$ & $9(20.9)$ & \\
\hline Number of children & & & $0.376^{\ddagger}$ \\
\hline One & $18(41.9)$ & $23(53.3)$ & \\
\hline Two & $17(39.5)$ & $11(25.6)$ & \\
\hline Three & $8(18.6)$ & $9(20.9)$ & \\
\hline Sufficiency of family income for expenses & & & $0.417^{\S}$ \\
\hline Completely sufficient & $1(2.3)$ & $2(4.7)$ & \\
\hline Relatively sufficient & $40(93.0)$ & $40(93.0)$ & \\
\hline Insufficient & $2(4.7)$ & $1(2.3)$ & \\
\hline Number of family members & & & $0.053^{\ddagger}$ \\
\hline 1 to 3 & $38(88.4)$ & $30(69.8)$ & \\
\hline 4 to 6 & $5(11.6)$ & $10(23.3)$ & \\
\hline Over 6 & $0(0.0)$ & $3(7.0)$ & \\
\hline Living with which member & & & $0.156^{\ddagger}$ \\
\hline Daughter-in-law & $2(4.7)$ & $6(14.0)$ & \\
\hline Son-in-law & $0(0.0)$ & $1(2.3)$ & \\
\hline None & $41(95.3)$ & $36(83.7)$ & \\
\hline Satisfaction of life & & & $1.000^{\S}$ \\
\hline Satisfied & $41(95.3)$ & $40(93.0)$ & \\
\hline Not Satisfied & $0(0.0)$ & $2(4.7)$ & \\
\hline No idea & $2(4.7)$ & $1(2.3)$ & \\
\hline Husband smoking & & & $0.610^{\ddagger}$ \\
\hline Yes & $9(20.9)$ & $11(25.6)$ & \\
\hline No & $34(79.1)$ & $32(74.4)$ & \\
\hline
\end{tabular}

${ }^{*}$ Standard Deviation; ${ }^{+}$Independent t-test; ${ }^{*}$ Fisher's exact test; ${ }^{5}$ Chi-square test for trend 
Table 2 Comparison of stress, anxiety and depression between study groups

\begin{tabular}{|c|c|c|c|c|c|}
\hline \multirow[t]{2}{*}{ Variable } & \multicolumn{2}{|c|}{ Counseling group $(n=43)$} & \multicolumn{2}{|c|}{ Control group $(n=43)$} & \multirow[t]{2}{*}{$P$-value } \\
\hline & Mean $\left(\mathrm{SD}^{\ddagger}\right)$ & Median (Per 25 to 75$)^{\S}$ & Mean $\left(\mathrm{SD}^{\ddagger}\right)$ & Median (Per 25 to 75$)^{¥}$ & \\
\hline \multicolumn{6}{|l|}{ Depression } \\
\hline Before intervention & $6.24(1.88)$ & 6.00 (5.00 to 7.00$)$ & $6.07(1.57)$ & 6.00 (5.00 to 7.00$)$ & $0.611^{*}$ \\
\hline After intervention & $1.98(1.59)$ & 2.00 (1.00 to 3.00$)$ & $3.59(1.91)$ & $3.00(2.00$ to 5.00$)$ & $<0.001^{*}$ \\
\hline Intra-group comparison (P-value $)^{*}$ & $<0.001$ & & $<0.001$ & & \\
\hline \multicolumn{6}{|l|}{ Anxiety } \\
\hline Before intervention & $6.89(1.82)$ & 7.00 (6.00 to 8.00$)$ & $6.38(1.47)$ & 6.00 (5.00 to 8.00$)$ & $0.189^{*}$ \\
\hline After intervention & $2.66(1.28)$ & 3.00 (2.00 to 4.00$)$ & $4.19(1.85)$ & 4.00 (2.00 to 6.00$)$ & $<0.001^{\dagger}$ \\
\hline Intra-group comparison ( $P$-value $)^{*}$ & $<0.001$ & & $<0.001$ & & \\
\hline \multicolumn{6}{|l|}{ Stress } \\
\hline Before intervention & $8.73(1.55)$ & 9.00 (8.00 to 9.00$)$ & $8.89(1.08)$ & 9.00 (8.00 to 9.00$)$ & $0.878^{*}$ \\
\hline After intervention & $2.91(1.62)$ & 3.00 (2.00 to 4.00$)$ & $5.61(1.49)$ & $5.00(5.00$ to 7.00$)$ & $<0.001^{\dagger}$ \\
\hline Intra-group comparison $(P \text {-value })^{*}$ & $<0.001$ & & $<0.001$ & & \\
\hline
\end{tabular}

${ }^{*}$ Mann Whitney U test; ${ }^{\dagger}$ Independent t-test; ${ }^{\ddagger}$ Mean (Standard Deviation); ${ }^{\S}$ Median (Percentile 25 to Percentile 75 );

* Wilcoxon test

hypertension. In this study, the results showed that this intervention reduces stress and anxiety in hypertensive patients [30]. The results of all mentioned studies are consistent with the present study.

The ACT based counseling encourages clients to accept internal experiences. One of the main strategies of this intervention is acceptance. It is a choice that means leaving the discomfort with its reasons. Acceptance is an alternative process of control. It allows clients to accept unpleasant inner experiences without trying to control them [53]. In this case, experiences seem less threatening and have less effect on a person's life. To help people gain control of their inner experiences, therapists use an acceptance and commitment-based approach with many metaphors and strategies [54].

The counseling did not affect the sleep quality of menopausal women in the present study. Rasouli et al. (2018) conducted a quasi-experimental study to investigate the effectiveness of acceptance and commitmentbased psychotherapy in improving depression and sleep quality in women with postpartum depression. The results showed that commitment and acceptancebased therapy is significantly effective in reducing postpartum depression and increasing sleep quality [55]. Zakiei et al. (2021) conducted a study to investigate the effect of acceptance and commitment-based counseling on sleep quality, experimental avoidance, and emotion regulation in people with insomnia. It showed that this intervention improves sleep quality, experimental avoidance, and emotion regulation [56]. Salari et al. (2020) also conducted a study to determine the impact of acceptance and commitment-based intervention on sleep quality and insomnia. This study results also showed that ACT counseling improves sleep quality and insomnia [57].

In the present study, counseling did not affect the quality of life of postmenopausal women. Rezaei et al. (2020) conducted a quasi-experimental study to compare the efficacy of ACT-based counseling and compassion-focused treatment on psychological well-being and quality of life in patients with immunodeficiency virus. Findings indicated that both acceptance and commitment-based therapy and compassion-focused therapy had a positive effect on psychological well-being and quality of life in patients with immunodeficiency virus [58]. Samani et al. (2019) conducted also a study to compare the effect of ACT based counseling and physiotherapy on quality of life and pain catastrophizing. It was concluded that the quality of life in people receiving ACT-based counseling was significantly higher than those receiving physiotherapy. There was no difference in reducing the rate of pain catastrophizing in the two groups [59]. Hassani et al. (2018) conducted a study to determine the effect of the ACT based counseling on the quality of life and resilience of women with breast cancer. In this study, the results showed that the ACT-based intervention improved the quality of life and resilience of women with breast cancer [27]. Vakilian et al. (2019) conducted a study to determine the effect of ACT on quality of life and stress of pregnant women. The results showed that this intervention improved the quality of life and stress of pregnant women immediately after the intervention. But, this effect decreased 1 month after the intervention [31].

In the present study, the results are not consistent with the results of the above studies on the effect of 
Table 3 Comparison of sleep quality and its subscales between study groups

\begin{tabular}{|c|c|c|c|c|c|}
\hline \multirow[t]{2}{*}{ Variable } & \multicolumn{2}{|c|}{ Counseling group $(n=43)$} & \multicolumn{2}{|c|}{ Control group $(n=43)$} & \multirow[t]{2}{*}{$P$-value } \\
\hline & Mean $\left(\mathrm{SD}^{\ddagger}\right)$ & Median (Per 25 to 75$)^{\S}$ & Mean $\left(\mathrm{SD}^{\ddagger}\right)$ & Median (Per 25 to 75$)^{\S}$ & \\
\hline \multicolumn{6}{|l|}{ Subjective sleep quality } \\
\hline Before intervention & $0.96(0.85)$ & $1.00(0.00$ to 1.00$)$ & $0.68(0.72)$ & $1.00(0.00$ to 1.00$)$ & $0.130^{*}$ \\
\hline After intervention & $0.54(0.67)$ & $0.00(0.00$ to 1.00$)$ & $0.56(0.71)$ & $0.00(0.00$ to 1.00$)$ & $0.926^{*}$ \\
\hline Intra-group comparison $(P \text {-value })^{*}$ & $<0.001$ & & 0.025 & & \\
\hline \multicolumn{6}{|l|}{ Sleep latency } \\
\hline Before intervention & $1.37(1.04)$ & 1.50 (0.50 to 2.50$)$ & $1.41(1.05)$ & 1.50 (0.00 to 2.50$)$ & $0.837^{\dagger}$ \\
\hline After intervention & $0.88(0.91)$ & 0.50 (0.00 to 1.50$)$ & $1.09(0.94)$ & 1.00 (0.00 to 2.00$)$ & $0.334^{*}$ \\
\hline Intra-group comparison (P-value $)^{*}$ & $<0.001$ & & $<0.001$ & & \\
\hline \multicolumn{6}{|l|}{ Sleep duration } \\
\hline Before intervention & $0.98(0.86)$ & $1.00(0.00$ to 1.00$)$ & $0.94(0.71)$ & $1.00(0.00$ to 1.00$)$ & $0.985^{*}$ \\
\hline After intervention & $0.70(0.71)$ & $1.00(0.00$ to 1.00$)$ & $0.70(0.64)$ & $1.00(0.00$ to 1.00$)$ & $0.920^{*}$ \\
\hline Intra-group comparison $(P \text {-value })^{*}$ & 0.001 & & 0.012 & & \\
\hline \multicolumn{6}{|l|}{ Sleep efficacy } \\
\hline Before intervention & $0.14(0.42)$ & 0.00 (0.00 to 0.00$)$ & $0.17(0.38)$ & 0.00 (0.00 to 0.00$)$ & $0.570^{*}$ \\
\hline After intervention & $0.05(0.22)$ & $0.00(0.00$ to 0.00$)$ & $0.05(0.22)$ & $0.00(0.00$ to 0.00$)$ & $1.000^{*}$ \\
\hline Intra-group comparison $(P \text {-value })^{*}$ & 0.046 & & 0.025 & & \\
\hline \multicolumn{6}{|l|}{ Sleep disturbance } \\
\hline Before intervention & $1.26(0.50)$ & 1.00 (1.00 to 2.00$)$ & $1.17(0.44)$ & $1.00(1.00$ to 1.00$)$ & $0.339^{*}$ \\
\hline After intervention & $1.17(0.49)$ & $1.00(1.00$ to 1.00$)$ & $1.05(0.31)$ & $1.00(1.00$ to 1.00$)$ & $0.165^{*}$ \\
\hline Intra-group comparison $(P \text {-value })^{*}$ & 0.102 & & 0.025 & & \\
\hline \multicolumn{6}{|l|}{ Use of sleeping medication } \\
\hline Before intervention & $0.63(1.03)$ & 0.00 (0.00 to 2.00$)$ & $0.38(0.66)$ & 0.00 (0.00 to 1.00$)$ & $0.466^{*}$ \\
\hline After intervention & $0.49(0.91)$ & $0.00(0.00$ to 1.00$)$ & $0.38(0.66)$ & $0.00(0.00$ to 1.00$)$ & $0.844^{*}$ \\
\hline Intra-group comparison $(P \text {-value })^{*}$ & 0.034 & & 1.000 & & \\
\hline \multicolumn{6}{|l|}{ Daytime dysfunction } \\
\hline Before intervention & $0.31(0.52)$ & 0.00 (0.00 to 1.00$)$ & $0.52(0.83)$ & 0.00 (0.00 to 1.00$)$ & $0.350^{*}$ \\
\hline After intervention & $0.24(0.43)$ & 0.00 (0.00 to 0.00$)$ & $0.33(0.57)$ & 0.00 (0.00 to 1.00$)$ & $0.546^{*}$ \\
\hline Intra-group comparison $(P \text {-value })^{*}$ & 0.008 & & 0.001 & & \\
\hline \multicolumn{6}{|l|}{ Total sleep quality score } \\
\hline Before intervention & $5.62(2.82)$ & $5.50(3.00$ to 7.50$)$ & $5.23(3.26)$ & $4.00(3.00$ to 7.50$)$ & $0.548^{\dagger}$ \\
\hline After intervention & $4.04(2.52)$ & $4.00(2.00$ to 5.50$)$ & $4.13(2.63)$ & $3.50(2.00$ to 6.00$)$ & $0.867^{\dagger}$ \\
\hline Intra-group comparison (P-value $)^{€}$ & $<0.001$ & & $<0.001$ & & \\
\hline
\end{tabular}

${ }^{\circ}$ Mann Whitney U test; ${ }^{\dagger}$ Independent t-test; ${ }^{\ddagger}$ Mean (Standard Deviation); ${ }^{\S}$ Median (Percentile 25 to Percentile 75 );

${ }^{*}$ Wilcoxon test; ${ }^{\epsilon}$ Paired samples t-test

ACT-based counseling on quality of sleep and life. This inconsistency may be attributed to variations of participants, and study time frame. The above mentioned studies have conducted on patients with immunodeficiency virus, women with breast cancer and pregnant women. The present study is the first study that assessed the effect of ACT-based counseling on quality of sleep and life among menopausal women. Numerous other factors affect the sleep quality of menopausal women such as neurological diseases, metabolic changes, weight gain and low levels of exercise, medications, lifestyle, and changes in hormone levels [60-62]. Also, in the present study, due to the concurrence of this study with the corona pandemic and its limitations such as quarantine and social distancing and the impact of this issue on different aspects of life, this intervention did not affect the quality of life and sleep. Quarantine in the COVID-19 epidemic has caused many changes in the lifestyle of most people [63]. In addition to the social and economic context, quarantine changed the cognitive and behavioral aspects of people's lives [64]. These forced changes in lifestyle habits due to quarantine, such as changes in interpersonal relationships, eating habits, exercise, or sex are more common in postmenopausal women. They 
Table 4 Comparison of quality of life and its subscales between study groups

\begin{tabular}{|c|c|c|c|c|c|}
\hline \multirow[t]{2}{*}{ Variable } & \multicolumn{2}{|c|}{ Counseling group $(n=43)$} & \multicolumn{2}{|c|}{ Control group $(n=43)$} & \multirow[t]{2}{*}{$P$-value } \\
\hline & Mean $\left(\mathrm{SD}^{\ddagger}\right)$ & Median (Per 25 to 75$)^{\S}$ & Mean $\left(\mathrm{SD}^{\ddagger}\right)$ & Median (Per 25 to 75$)^{\S}$ & \\
\hline \multicolumn{6}{|l|}{ Vasomotor } \\
\hline Before intervention & $6.07(4.33)$ & 6.00 (3.00 to 9.00$)$ & $5.26(3.37)$ & 4.00 (3.00 to 8.00$)$ & $0.333^{\dagger}$ \\
\hline After intervention & $4.07(3.31)$ & $3.00(2.00$ to 6.00$)$ & $4.45(3.18)$ & $4.00(2.00$ to 6.00$)$ & $0.451^{*}$ \\
\hline Intra-group comparison $(P \text {-value })^{*}$ & $<0.001$ & & $<0.001$ & & \\
\hline \multicolumn{6}{|l|}{ Psychosocial } \\
\hline Before intervention & $5.87(7.75)$ & 4.00 (0.00 to 9.00$)$ & $3.77(5.51)$ & 1.00 (0.00 to 5.00$)$ & $0.222^{*}$ \\
\hline After intervention & $3.66(5.15)$ & 2.00 (0.00 to 5.00$)$ & $3.12(4.52)$ & 1.00 (0.00 to 5.00$)$ & $0.435^{*}$ \\
\hline Intra-group comparison $(P \text {-value })^{*}$ & $<0.001$ & & 0.002 & & \\
\hline \multicolumn{6}{|l|}{ Physical } \\
\hline Before intervention & $17.35(13.57)$ & 12.00 (9.00 to 24.00$)$ & $16.80(13.35)$ & 12.00 (8.00 to 16.00$)$ & $0.976^{*}$ \\
\hline After intervention & $14.03(12.3)$ & $10.00(5.00$ to 18.00$)$ & $14.33(11.88)$ & $10.00(7.00$ to 14.00$)$ & $0.565^{*}$ \\
\hline Intra-group comparison $(P \text {-value })^{*}$ & $<0.001$ & & $<0.001$ & & \\
\hline \multicolumn{6}{|l|}{ Sexual } \\
\hline Before intervention & $2.19(4.14)$ & 0.00 (0.00 to 2.00$)$ & $1.42(2.89)$ & 0.00 (0.00 to 1.00$)$ & $0.431^{*}$ \\
\hline After intervention & $1.73(3.44)$ & $0.00(0.00$ to 1.00$)$ & $1.26(2.66)$ & 0.00 (0.00 to 1.00$)$ & $0.705^{*}$ \\
\hline Intra-group comparison $(P \text {-value })^{*}$ & 0.004 & & 0.176 & & \\
\hline \multicolumn{6}{|l|}{ Total quality of life score } \\
\hline Before intervention & $31.47(24.55)$ & 24.00 (14.00 to 42.00$)$ & $27.24(19.99)$ & 21.00 (13.00 to 29.00$)$ & $0.457^{*}$ \\
\hline After intervention & $23.47(20.13)$ & $18.00(9.00$ to 28.00$)$ & $23.14(17.76)$ & $17.00(10.00$ to 26.00$)$ & $0.759^{*}$ \\
\hline Intra-group comparison $(P \text {-value })^{*}$ & $<0.001$ & & $<0.001$ & & \\
\hline
\end{tabular}

${ }^{*}$ Mann Whitney $\mathrm{U}$ test; ${ }^{\dagger}$ Independent $\mathrm{t}$-test; ${ }^{\ddagger}$ Mean (Standard Deviation); ${ }^{\S}$ Median (Percentile 25 to Percentile 75 );

* Wilcoxon test

can exacerbate their menopausal symptoms and cause a loss of quality of life [65]. COVID-19 pandemic and quarantine have caused changes in the program, quality, and quantity of sleep such as going to bed late at night, waking up late in the morning, and reducing the quality of sleep and daily naps according to recent studies [66]. Some factors lead to circadian rhythm disturbances such as reduced exposure to sunlight, restriction of daily activities, and changes in meal times which can affect people's sleep $[67,68]$.

\section{Strengths and limitations}

One of the strengths of this study is observing all principles of randomized controlled trial, including random allocation and allocation concealment. Standard and valid questionnaires were used in this study, which the psychometric properties of these questionnaires have been assessed in Iran already. There was no attrition in this study. The limitation of this study was that it coincided with the coronavirus pandemic and severe restrictions due to social distancing and quarantine for counseling sessions. In addition, it was not possible to blind the participants and data assessor due to the nature of the intervention. Also, due to the non-normal distribution of data, the two-way ANOVA test wasn't conducted.
Other limitations are that sample size of this study was relatively small and the follow-up period was short. Therefore, it is recommended to conduct randomized clinical trials with larger sample size and longer followup period. Also, it is recommended that the similar study to be conducted after the end of coronavirus pandemic.

\section{Conclusion}

One of the important goals of health care is promoting women's mental health during menopause. Using ACTbased counseling can improve the mood of menopausal women. However, further randomized clinical trials are needed before making a definitive conclusion. Since, the counseling with ACT approach is easy, effective and understandable for women and also the healthcare services are provided free-of-charge in health centers of Iran, therefore, with the training of health care providers, they can improve the health of menopausal women by properly using of this approach.

\footnotetext{
Abbreviations

ACT: Acceptance and Commitment Therapy; DASS 21: Depression, Anxiety Stress Scale-21; MENQOL: Menopause Quality of Life; PSQI: Pittsburgh Sleep Quality Index; SD: standard deviation; IRCT: Iranian Registry of Clinical Trials; FSH: Follicular Stimulating Hormone; HRT: Hormone Therapy; BMI: Body Mass Index.
} 


\section{Acknowledgements}

This study was part of a master's thesis in counseling in midwifery. The authors appreciate the assistance and cooperation of the Deputy of Research of Tabriz University of Medical Sciences for their support in this research as well as all participants of this study.

\section{Authors' contributions}

ZM involved in the conception and design, acquisition of data and drafting the manuscript. JM involved in the conception and design, acquisition of data blinded analysis of the data, interpretation of data and writing this manuscript. MF involved in the conception and design, implementation of counseling sessions and revising this manuscript. MM involved in the conception and design, acquisition of data, blinded analysis of the data, interpretation of data and writing this manuscript. All authors gave their final approval of this version to be published.

\section{Funding}

This research is supported by Tabriz University of Medical Sciences. The funding source had no involvement in design of the study, data collection, data analysis, etc.

\section{Availability of data and materials}

The datasets used and/or analysed during the current study available from the corresponding author on reasonable request.

\section{Declarations}

\section{Ethics approval and consent to participate}

This research has been approved by the Ethics Committee of the Tabriz University of Medical Sciences, Tabriz, Iran (code number: IR.TBZMED. REC.1399.1033). All participants were ensured about the matter of confidentiality. Also, informed written consent was obtained from all participants and parent/legally authorized representatives of illiterate participants. All methods were performed in accordance with the Declaration of Helsinki.

\section{Consent for publication}

Not applicable.

\section{Competing interests}

The authors declare that they have no competing interests.

\section{Author details}

${ }^{1}$ Department of midwifery, Faculty of Nursing and Midwifery, Tabriz University of medical sciences, Tabriz, Iran. ${ }^{2}$ Midwifery Department, Tabriz University of Medical Sciences, Tabriz, Iran. ${ }^{3}$ Clinical Psychologist, Razi Hospital, Tabriz University of Medical Sciences, Tabriz, Iran. ${ }^{4}$ Social Determinants of Health Research Center, Faculty of Nursing and Midwifery, Tabriz University of Medical Sciences, Shariati Street, P.O. Box: 51745-347, Tabriz 513897977, Iran. ${ }^{5}$ Department of Family Health, Social Determinants of Health Research Center, Ardabil University of Medical Sciences, Ardabil, Iran.

Received: 3 October 2021 Accepted: 9 February 2022

Published online: 11 February 2022

\section{References}

1. Taibi DM, Vitiello MV, Barsness S, Elmer GW, Anderson GD, Landis CA A randomized clinical trial of valerian fails to improve self-reported, polysomnographic, and actigraphic sleep in older women with insomnia. Sleep Med. 2009;10(3):319-28.

2. Taavoni S, Ekbatani N, Kashaniyan M, Haghani H. Effect of valerian on sleep quality in postmenopausal women: a randomized placebo-controlled clinical trial. Menopause. 2011;18(9):951-5.

3. Metcalf $M$, Donald R. Fluctuating ovarian function in a perimenopausal women. N Z Med J. 1979;89(628):45-7.

4. Abedzadeh-Kalahroudi M, Taebi M, Sadat Z, Saberi F, Karimian Z. Prevalence and severity of menopausal symptoms and related factors among women 40-60 years in Kashan, Iran. Nurs Midwifery Stud. 2012;1(2):88-93.
5. Askari F, Basiri MK, Basiri MM, Torabi S, Gholamfarkhani S, Mohareri M, et al. Age of natural menopause and the comparison of incidence of its early complications in menopause transition stages in women from Gonabad city. Horiz Med Sci. 2012;17(4):42-8.

6. Xu J, Bartoces M, Neale AV, Dailey RK, Northrup J, Schwartz KL. Natural history of menopause symptoms in primary care patients: a MetroNet study. J Am Board Fam Pract. 2005;18(5):374-82.

7. Mohammad K, Hashemi SMS, Farahani FKA. Age at natural menopause in Iran. Maturitas. 2004:49(4):321-6.

8. Youngkin E, Davis M, Schadewald D, Juve C. Women's health: A primary care clinical guide. 4th edition. New Jersey: Pearson Higher Education; 2012.

9. Appt SE, Clarkson TB, Hoyer PB, Kock ND, Goode AK, May MC, et al. Experimental induction of reduced ovarian reserve in a nonhuman primate model (Macaca fascicularis). Compa Med. 2010;60(5):380-8.

10. Gudmundsdottir S, Flanders W, Augestad L. Physical activity and cardiovascular risk factors at menopause: the Nord-Trøndelag health study. Climacteric. 2013;16(4):438-46.

11. Cohen LS, Soares CN, Joffe H. Diagnosis and management of mood disorders during the menopausal transition. Am J Med. 2005 Dec 19:118(12):93-7.

12. Zweifel JE, O'Brien WH. A meta-analysis of the effect of hormone replacement therapy upon depressed mood. Psychoneuroendocrinology. 1997;22(3):189-212

13. Lang A, Stein M. Anxiety disorders. How to recognize and treat the medical symptoms of emotional illness. Geriatrics. 2001;56(5):24-7 31.

14. Núñez-Pizarro JL, González-Luna A, Mezones-Holguín E, Blümel JE, Barón $\mathrm{G}$, Bencosme $\mathrm{A}$, et al. Association between anxiety and severe qualityof-life impairment in postmenopausal women: analysis of a multicenter Latin American cross-sectional study. Menopause. 2017;24(6):645-52.

15. Bauld R, Brown RF. Stress, psychological distress, psychosocial factors, menopause symptoms and physical health in women. Maturitas. 2009;62(2):160-5

16. Eftekhar T. Menopause early to late. Tehran: Noavar; 2005. p. 109-12.

17. Gooneratne NS. Complementary and alternative medicine for sleep disturbances in older adults. Clin Geriatr Med. 2008;24(1):121-38.

18. Cooke JR, Ancoli-Israel S. Sleep and its disorders in older adults. Psychiatr Clin. 2006;29(4):1077-93.

19. Obermeyer CM, Reynolds RF, Price K, Abraham A. Therapeutic decisions for menopause: results of the DAMES project in Central Massachusetts. Menopause. 2004;11(4):456-65.

20. Freeman EW, Grisso JA, Berlin J, Sammel M, Garcia-Espana B, Hollander L. Symptom reports from a cohort of African American and white women in the late reproductive years. Menopause. 2001;8(1):33-42.

21. MacLennan AH, Broadbent JL, Lester S, Moore V. Oral oestrogen and combined oestrogen/progestogen therapy versus placebo for hot flushes. Cochrane Database Syst Rev. 2004;4:CD002978.

22. Nelson HD, Vesco KK, Haney E, Fu R, Nedrow A, Miller J, et al. Nonhormonal therapies for menopausal hot flashes: systematic review and metaanalysis. JAMA. 2006:295(17):2057-71.

23. Malcomson K, Dunwoody L, Lowe-Strong A. Psychosocial interventions in people with multiple sclerosis. J Neurol. 2007;254(1):1-13.

24. Hayes SC, Luoma JB, Bond FW, Masuda A, Lillis J. Acceptance and commitment therapy: model, processes and outcomes. Behav Res Ther. 2006;44(1):1-25.

25. Hayes SC, Levin ME, Plumb-Vilardaga J, Villatte JL, Pistorello J. Acceptance and commitment therapy and contextual behavioral science: examining the progress of a distinctive model of behavioral and cognitive therapy. Behav Ther. 2013:44(2):180-98.

26. Hiratzka J, Rastegar F, Contag AG, Norvell DC, Anderson PA, Hart RA. Adverse event recording and reporting in clinical trials comparing lumbar disk replacement with lumbar fusion: a systematic review. Global Spine J. 2015;5(6):486-95

27. Hassani F, Emamipour S, Mirzaei H. Effect of acceptance and commitment group therapy on quality of life and resilience of women with breast cancer. Arch Breast Cancer. 2018:111-7.

28. Rajabi S, Yazdkhasti F. The effectiveness of acceptance and commitment group therapy on anxiety and depression in women with MS who were referred to the MS association. J Clin Psychol. 2014;6(1):29-38.

29. Gharashi K, Moheb N, Abdi R. Effects of acceptance and commitment therapy on decreasing anxiety and depression symptoms in mothers of hearing-impaired or deaf children. Aud Vestib Res. 2019;28(2):116-23. 
30. Miri M, Vaziri S, Ahi Q, Shahabizadeh F, Mahmoudirad A. The effects of acceptance and commitment therapy on depression and anxiety in patients with hypertension. Qom Univ Med Sci J. 2021;15(1):66-75.

31. Vakilian K, Zarei F, Majidi A. Effect of acceptance and commitment therapy (ACT) on anxiety and quality of life during pregnancy: A mental health clinical trial study. Iran Red Cresc Med J. 2019;21(8):e89489.

32. Rostamkhani F, Ghamari M, Babakhani V, Merghati KE. The effect of acceptance and commitment therapy on sexual function in postmenopausal women. J Health Care. 2020;22(2):102-13.

33. Hunter M. Cognitive behavioral therapy for menopausal symptoms. Climacteric. 2021;24(1):51-6.

34. Reddy NV, Omkarappa DB. Cognitive-behavioral therapy for depression among menopausal woman: a randomized controlled trial. J Fam Med Prim Care. 2019;8(3):1002

35. Moghani SS, Simbar M, Dolatian M, Nasiri M. The relationship between perceived social support and women experiences in menopause. Adv Nurs Midwifery. 2016;25(90):55-64.

36. Habibi M, Hanasabzadeh M. The effectiveness of mindfulness based art therapy on depression, anxiety, stress and quality of life among postmenopausal women. Iran J Ageing. 2014;9(1):22-31.

37. Tarvardi M, Shabani A. Assessment of psychological problems in menopause women and relationship's between individual and social characteristic and menopausal symptoms in referred to Tabriz educational hospitalS in 2005-2006. J Urmia Nurs Midwifery Fac. 2007;5(1):37-45.

38. Harvey AG, Gumport NB. Evidence-based psychological treatments for mental disorders: modifiable barriers to access and possible solutions. Behav Res Ther. 2015:68:1-12.

39. Carlson LE, Bultz BD. Benefits of psychosocial oncology care: improved quality of life and medical cost offset. Health Qual Life Outcomes. 2003;1(1):1-9.

40. Carlson LE, Bultz BD. Efficacy and medical cost offset of psychosocial interventions in cancer care: making the case for economic analyses. Psychooncology. 2004;13(12):837-49.

41. Shariat Moghani S, Ebrahimzadeh M, Safari A, Jamali J. The effectiveness of husbands'awareness of menopausal complications on physical psychological experiences of postmenopausal women. J Holist Nurs Midwifery. 2021;31(3):155-64.

42. Erdfelder E, Faul F, Buchner A. GPOWER: a general power analysis program. Behav Res Methods Instrum Comput. 1996 Mar;28(1):1-1.

43. Sealed Envelope Ltd. 2021. Create a blocked randomisation list. [Online] Available from: https://www.sealedenvelope.com/simple-randomiser/v1/ lists Accessed 11 Jan 2022

44. Parsa P, Tabesh RA, Soltani F, Karami M. Effect of group counseling on quality of life among postmenopausal women in Hamadan, Iran. J Menopausal Med. 2017;23(1):49-55.

45. Yazdkhasti M, Keshavarz M, Merghati Khoei E, Hosseini AF. The effect of structured educational program by support group on menopause women's quality of life. Iran J Med Edu. 2012;11(8):986-94.

46. Smyth C. The Pittsburgh sleep quality index (PSQI). New Jersey: SLACK Incorporated; 1999.

47. Nazifi M, Mokarami H, Akbaritabar AA, Kalte HO, Rahi A. Psychometric properties of the Persian translation of Pittsburgh sleep quality index. Health Scope. 2014;3(2):e15547.

48. Parkitny L, McAuley J. The depression anxiety stress scale (DASS). J Physiother. 2010:56(3):204

49. Wise FM, Harris DW, Olver JH. The DASS-14: improving the construct validity and reliability of the depression, anxiety, and stress scale in a cohort of health professionals. J Allied Health. 2017:46(4):85E-90E.

50. Henry JD, Crawford JR. The short-form version of the depression anxiety stress scales (DASS-21): construct validity and normative data in a large non-clinical sample. Br J Clin Psychol. 2005;44(2):227-39.

51. Sahebi A, Asghari MJ, Salari RS. Validation of depression anxiety and stress scale (DASS-21) for an Iranian population. J Dev Psychol. 2005;1 (4):36-54.

52. Heydari M, Masafi S, Jafari M, Saadat SH, Shahyad S. Effectiveness of acceptance and commitment therapy on anxiety and depression of Razi psychiatric center staff. Maced J Med Sci. 2018:6(2):410.

53. Blackledge JT, Hayes SC. Emotion regulation in acceptance and commitment therapy. J Clin Psychol. 2001;57(2):243-55.

54. Wells A, Fisher P, Myers S, Wheatley J, Patel T, Brewin CR. Metacognitive therapy in treatment-resistant depression: a platform trial. Behav Res Ther. 2012:50(6):367-73.
55. Rasouli A. Effectiveness of acceptance and commitment psychotherapy in improving depression and quality of sleep in women with postpartum depression. Iran J Nurs Res. 2019;14(1):21-8.

56. Zakiei A, Khazaie H, Rostampour M, Lemola S, Esmaeili M, Dürsteler $K$, et al. Acceptance and commitment therapy (ACT) improves sleep quality, experiential avoidance, and emotion regulation in individuals with insomnia - results from a randomized interventional study. Life. 2021;11(2):133

57. Salari N, Khazaie H, Hosseinian-Far A, Khaledi-Paveh B, Ghasemi H, Mohammadi $\mathrm{M}$, et al. The effect of acceptance and commitment therapy on insomnia and sleep quality: a systematic review. BMC Neurol. 2020;20(1):1-18.

58. Rezaei S, Khalatbari J, Kalhorniagolkar M, Tajeri B. Comparison of the effectiveness of two models of acceptance and commitment therapy and compassion focused therapy on psychological well-being and quality of life of individuals with human immunodeficiency viruses. J Health Care. 2020;22(3):245-56.

59. Samani MG, Najafi M, Bouger IR. Comparing the effectiveness of acceptance and commitment therapy and physiotherapy on quality of life and pain catastrophizing in patients with chronic pain. J Shahrekord Univ Med Sci. 2019;21(6):271-5.

60. Antonijevic IA, Stalla GK, Steiger A. Modulation of the sleep electroencephalogram by estrogen replacement in postmenopausal women. Am J Obstet Gynecol. 2000;182(2):277-82

61. Polo-Kantola P, Erkkola R, Helenius H, Irjala K, Polo O. When does estrogen replacement therapy improve sleep quality? Am J Obstet Gynecol. 1998:178(5):1002-9.

62. Svensson M, Lindberg E, Naessen T, Janson C. Risk factors associated with snoring in women with special emphasis on body mass index: a population-based study. Chest. 2006;129(4):933-41.

63. Galli F, Reglero G, Bartolini D, Visioli F. Better prepare for the next one. Lifestyle lessons from the COVID-19 pandemic. PharmaNutrition. 2020;12:100193.

64. Ferreira LN, Pereira LN, da Fé BM, Ilchuk K. Quality of life under the COVID19 quarantine. Qual Life Res. 2021;30(5):1389-405.

65. Vélez Toral M, Godoy-Izquierdo D, Padial García A, Lara Moreno R, Mendoza Ladrón de Guevara N, Salamanca Ballesteros A, et al. Psychosocial interventions in perimenopausal and postmenopausal women: a systematic review of randomised and non-randomised trials and non-controlled studies. Maturitas. 2014;77(2):93-110.

66. Gupta R, Grover S, Basu A, Krishnan V, Tripathi A, Subramanyam A, et al. Changes in sleep pattern and sleep quality during COVID-19 lockdown. Indian J Psychiatry. 2020;62(4):370-8.

67. Silva FRD, Guerreiro RC, Andrade HA, Stieler E, Silva A, de Mello MT. Does the compromised sleep and circadian disruption of night and shiftworkers make them highly vulnerable to 2019 coronavirus disease (COVID19)? Chronobiol Int. 2020;37(5):607-17.

68. van de Langenberg D, Vlaanderen JJ, Dollé MET, Rookus MA, van Kerkhof LWM, Vermeulen RCH. Diet, physical activity, and daylight exposure patterns in night-shift workers and day workers. Ann Work Expo Health. 2019;63(1):9-21.

\section{Publisher's Note}

Springer Nature remains neutral with regard to jurisdictional claims in published maps and institutional affiliations. 